\title{
A Filosofia da História de Benjamin Constant
}

\section{Benjamin Constant's Philosophy of History}

\section{Gabriel Afonso Campos}

Mestrando em direito na UFMG

Resumo: Em uma tentativa de contribuir para um resgate do pensamento constantiano de forma completa, o trabalho pretende explorar a Filosofia da História de Benjamin Constant demostrando os pontos de convergência entre ela e o pensamento de Immanuel Kant. Percebe-se que Constant utiliza-se do princípio da igualdade como forma de interpretar a História, enquanto Kant se utiliza da liberdade para tal. O ideal buscado por ambos, contudo, aproxima-se de uma sociedade simultaneamente livre e igual.

Palavras-chave: Benjamin Constant; Immanuel Kant; Filosofia da História.

Abstract: In an attempt to contribute to a complete rescue of constantian thought, the paper intends to explore Benjamin Constant's Philosophy of History by demonstrating the points of convergence between it and Immanuel Kant's thought. It is perceived that Constant uses the principle of equality as a way of interpreting History, while Kant uses freedom to do that. The ideal pursued by both, however, approaches a society that is both free and equal.

Keywords: Benjamin Constant; Immanuel Kant; Philosophy of History. 


\section{Introdução}

$\mathbf{O}$ legado político e intelectual de Henri-Benjamin Constant de Rebecque são rapidamente esquecidos após sua morte em 1830, seja por razões pessoais (como a obsessão de seus opositores políticos pela sua vida privada e sua religião protestante) ou por razões de ordem social, política e econômica (por exemplo, o seu silêncio sobre questões econômicas que então se tornavam latentes, bem como sua defesa dos direitos individuais em uma sociedade francesa pós-revolucionária ansiosa por pacificação e harmonia). Sua obra, assim, permaneceu em grande parte desconhecida até o século XX. Durante as décadas de 1970 e 1980, com o declínio dos estudos marxistas na França, o pensamento de Constant é redescoberto e o período da Restauração $0^{68}$, no qual ele efetivamente atinge o auge de sua carreira política, é visto como uma época de intensa reflexão política e o francês é, então, alçado a um dos pais do pensamento liberal. A leitura de Constant desse tempo, contudo, é fragmentária e o coloca como um pessimista, cético e suspeito em relação ao próprio ideal de democracia. O pensamento político francês recente, todavia, busca compreender Constant de forma completa, não-fragmentada, e inserido em seu contexto histórico ímpar e atribulado (ROSENBLATT, 2009, p. 352 e ss).

Nesse sentido, é mister redescobrir a obra de Constant em toda sua completude. Tal tarefa deve ser informada, antes de qualquer coisa, pela análise de sua Filosofia da História, dado que os pontos de vistas ali expressos podem relativizar os conceitos elaborados por ele ao longo de sua obra. Vista a pouca expressividade do pensamento do francês nas discussões acadêmicas brasileiras, seu estudo comparado com os autores de maior renome que lhe são contemporâneos (Immanuel Kant, no presente trabalho) é necessário. Considerado ainda o caráter eminentemente ilustrado de sua Filosofia da História, o trabalho se propõe a analisar a interpretação que Constant faz do fenômeno histórico, bem como as semelhanças que há nessa leitura com aquela feita por Kant alguns anos antes. A tentativa de se situar tal aporte ora próximo à Ilustração, ora próximo ao romantismo é, todavia, demasiado complexa.

68 Sobre o pensamento político do período, ver ROSANVALLON (2015). 
A Filosofia da História de Constant surge em momentos de sua vida distanciados por um período de mais de 30 anos. O primeiro texto no qual o tema é abordado é seu ensaio $D a$ força do governo atual da França e da necessidade de apoiá-lo, publicado em 1796, cujo objetivo era uma defesa do governo do Diretório, iniciado no ano anterior. O tema da Filosofia da História surge brevemente sintetizado em seu final: "a origem do Estado social é um grande enigma, mas sua marcha é simples e uniforme. Ao sair da nuvem impenetrável, que cobre seu nascimento, vemos o gênero humano avançar em direção à igualdade, sobre os destroços das instituições de todo gênero" (CONSTANT, 2001, p. 224).

Considerações semelhantes a essas aparecem, mais uma vez, na coletânea de ensaios, publicada em 1829, Mélanges de littérature et de politique, especificamente no ensaio denominado De la perfectibilité de l'espèce humaine. Nesse texto, cuja gênese teria se iniciado entre 1802 e $1804^{69}$, as ideias de Constant sobre um progressivo desenvolvimento da natureza humana são expostas de forma mais sistemática e estendida que no texto anterior e em outros fragmentos da obra constantiana na qual a temática também surge de forma mais ou menos marginal e difusa ${ }^{70}$, derivando daí seu uso nesse artigo. A ideia de perfectibilidade da espécie humana, isto é, sua capacidade de se aperfeiçoar, de se tornar cada vez melhor, ao longo do curso do tempo, é o leitmotiv da Filosofia da História de Constant.

O tema da perfectibilidade, que aparece frequentemente no pensamento ilustrado, em 1829, soaria anacrônico, embora a ideia de progresso não tenha sido abdicada pelo pensamento político do século XIX (basta pensar em Marx e em Comte) (HOFMANN, 2009, p. 248, 269-270) ${ }^{71}$. A questão, de fato, aparece em Kant, para quem "o ser humano deve a si mesmo (como um ser humano) não deixar ocioso e, por assim dizer, enferrujando as predisposições e faculdades naturais que 69 Nesse sentido, ver o estudo sobre a gênese do texto em HOFMANN (2009).

70 Como, por exemplo, CONSTANT (2008) e CONSTANT (2015).

${ }^{71}$ Sobre a prevalência do tema na História da Filosofia, ver PASSMORE (2000). 
sua razão pode algum dia usar" (KANT, 2003, p. 286). E ainda: "a natureza quis que o homem tire totalmente de si tudo o que ultrapassa o arranjo mecânico da sua existência animal, e que não participe de nenhuma outra felicidade ou perfeição exceto a que ele conseguiu para si mesmo, liberto do instinto, através da própria razão" (KANT, 2002, p. 389).

A perspectiva soa ainda mais anacrônica se percebermos o respeito que Constant nutre pelo passado e pelas tradições e por sua classificação entre os liberais românticos. Para o francês, instituições políticas herdadas do passado são preferíveis àquelas teoreticamente perfeitas, sob o risco de se cair numa estado de autoritarismo para sua implementação ${ }^{72}$ :

eu sinto pelo passado, o confesso, uma grande veneração; e a cada dia que passa, à medida que a experiência me instruí ou a reflexão me ilumina, essa veneração aumenta. E direi, para escândalo dos nossos modernos reformadores, tanto se se dão o título de Licurgo como o de Carlos Magno, que, se eu soubesse de um povo ao qual ofereceram instituições mais perfeitas, metafisicamente falando, e que as rejeitou para permanecer fiel às de seus pais, estimaria esse povo e os consideraria mais ditoso, por sua sensibilidade e sua consciência com essas instituições defeituosas, do que poderia se tornar com todos os aperfeiçoamentos propostos (CONSTANT, 2008, p. 58-59) ${ }^{73}$.

$72 \quad$ Para Constant (2007, p. 538-539), “é evidente que diferentes parcelas do mesmo povo, submetidas a circunstâncias, vivendo com costumes e morando em localidades que são todas dissimilares, não podem ser levadas absolutamente aos mesmos modos, usos, práticas e leis sem que haja coerção, a qual lhes custa mais do que vale. [...] Foi pelo sacrifício de tudo à ideia exagerada de uniformidade que os grandes Estados se transformaram em flagelos da humanidade. A renúncia a essa perfeição idealizada traria para os grandes Estados as vantagens dos pequenos e as combinariam com aquelas que derivam das grandes dimensões".

73 Tradução minha de "yo siento por el pasado, lo confieso, una gran veneración; y cada día que pasa, a medida que la experiencia me instruye o que la reflexión me ilumina, esa veneración aumenta. Y diré, para escándalo de nuestros modernos reformadores, tanto si se dan el título de Licurgo como el de Carlomagno, que si yo supiese de un pueblo que hubieran ofrecido las instituciones más perfectas, metafísicamente hablando, y que las hubiera rechazado para permanecer fiel a las de sus padres, estimaría a ese pueblo e le consideraría más dichoso, por su sensibilidad y su conciencia, con esas instituciones defectuosas, de lo que podría llegar a ser con todos los perfeccionamientos propuestos". 
Daí a afirmação de que a natureza humana é mutável e jamais estática, de forma que não pode ser apreendida pelas faculdades do indivíduo de uma vez por todas. Há estruturas políticas, sociais, econômicas, culturais e morais que podem existir em um determinado período por circunstâncias dadas num contexto - como o desenvolvimento tecnológico, a geografia, clima, o aprendizado social feito até aí, as instituições já existentes, sua plasticidade ou não etc. Assim, "fazem parte da natureza humana possibilidades contrárias que se atualizam ou não na dependência de um contexto histórico global" (BARROS, 1971, p. 121). Esse posicionamento situa Constant distante da razão geométrica, a-histórica, natural e uniforme dos ilustrados e o insere no contexto do liberalismo romântico, e não no liberalismo ético típico da Ilustração ${ }^{74}$.

A estrutura argumentativa encontrada no texto de Constant de 1829, entretanto, é semelhante o suficiente para justificar uma análise cotejada com alguns aspectos da Filosofia da História kantiana. E é esse objetivo que será perseguido por este trabalho, embora, desde já, eu assuma sua efemeridade e a possibilidade de novas discussões futuras sobre a questão.

\section{A Metafísica do conhecimento}

A Filosofia da História de Constant pode ser dividida em três partes: a afirmação de uma lei natural da perfeição; sua extensão para a espécie humana; e as provas empíricas de sua existência. Voltada para o futuro e consciente de que a Humanidade caminha progressivamente em direção à igualdade confere um teor ilustrado ao seu argumento, fato este que causa estranheza, posto que a publicação de seu ensaio De la perfectibilité de l'espèce humaine ocorre quando os ideias românticos já impregnavam o pensamento político e filosófico europeu (HOFMANN, 2009, p 250-256) ${ }^{75}$.

\footnotetext{
$74 \quad$ A classificação é do supracitado Barros (1971).

75 Hofmann nos lembra que esse ensaio foi provavelmente escrito em 1805 quando Constant teve acesso a obras de Herder e contato com Charles de Villers, o qual introduzira a Filosofia kantiana na França pós-revolucionária. O texto foi publicado apenas posteriormente em um livro maior como
} 
A afirmação de que há uma lei natural inscrita na natureza humana que permite o seu aperfeiçoamento é acompanhada de uma metafísica do conhecimento centrada no indivíduo. Assim, Constant defende a tese de que todas as impressões que o homem obtém da realidade são a ele transmitidas através dos sentidos, isto é, das modificações que o mundo exterior causa sobre o corpo humano e seus órgãos. Essas modificações são denominadas por ele de impressões e dividem-se em duas: ideias e sensações. Ambas têm origem na mesma relação entre sentido e ambiente exterior, porém se distinguem quanto à capacidade de se agruparem, de perdurarem e de modificarem os nossos órgãos (CONSTANT, 1829, p. 390).

As sensações, propriamente ditas, são aquelas impressões "passageiras, isoladas e [que] não deixam vestígios de sua existência senão a modificação física que produziram em nossos órgãos"76. Elas não possuem duração e, apesar de poderem ser classificadas pelo ser humano, não se encadeiam entre si, isto é, não se agrupam, não geram outras sensações. Mesmo que haja uma multiplicidade de sensações, elas existem apenas isoladamente. As ideias, por outro lado, são ou a memória das sensações passadas ou a combinação de ideias já existentes que, a partir dai, tornam-se novas ideias (CONSTANT, 1829 , p. $390-391)^{77}$.

uma tentativa de ingresso na Academia Francesa (WOOD, 2009, p. 17). A compreensão do tempo constantiana é projetada para o futuro e adquire uma visão linear e progressiva da História. A temporalidade é concebida "como uma experiência que se acumula com os séculos, assim como uma espécie de memória". Mesmo que pareça, sob um olhar mais particularizado, regredir, a História é sempre um "processo ascendente e irreversível". É partir dessas formulações que se pode, para Constant, responder à questão para onde vamos? (BARROSO, 2011, p. 58).

76 Tradução minha de "[...] passagères, isolées, et ne laissent d'autre trace de leur existence que la modification physique qu'elles ont produite sur nos organes".

77 Constant filia-se, aqui, a uma visão empirista do conhecimento, isto é, assume que as percepções advindas do mundo exterior produzem o nosso conhecimento e as divide em dois grupos: aquelas oriundas do contato direto dos órgãos sensoriais com a realidade física e outras que são lembrança desse contato. A mesma construção teórica pode ser encontrada em HUME (2009), LOCKE (2014), autores com os quais Constant provavelmente teve contato na Escócia, onde reside entre 1783 e 1785. 
Assim, utilizando-se como exemplo um homem desabrigado em um ambiente gélido, pode-se dizer, a partir dos pressupostos de Constant, que a interação entre o clima e a pele do homem é uma impressão que gera a sensação de frio. A lembrança dessa sensação, no futuro, ou sua combinação com outra ideia ou outra sensação (como, por exemplo, a memória do conforto de um casaco ou esse conforto efetivamente fruído) gerará, no homem, a ideia, o raciocínio, de vestir-se ou de fazer uma roupa para se aquecer.

Para o francês, as ideias, ao contrário das sensações, podem constituir uma propriedade real para o homem. De fato, tanto para receber as sensações quanto as ideias, Constant afirma que o homem está na dependência dos seus sentidos e dos objetos externos, mas as últimas, ao contrário das primeiras, permanecem na mente humana mesmo que o indivíduo não consiga lembrar-se delas e multiplicam-se e combinam-se uma pelas outras com ou sem o consentimento do intelecto humano (CONSTANT, 1829, p. 392) ${ }^{78}$.

A chave de compreensão da Filosofia da História de Constant consiste na tríade impressão, sensação e ideia e no ato humano de conhecer a realidade. Para ele, é "na comparação da influência das sensações propriamente ditas com aquilo que chamamos de ideias" que "está a solução do problema da perfectibilidade humana" (CONSTANT, 1829, p. 391) ${ }^{79}$.

Há, para Constant, uma única forma de aperfeiçoamento do homem e, a partir disso, da espécie e da cultura que lhe acompanha ao longo da História. Tal meio é o guiar-se pelas ideias, e não pelas sensações. Se o homem se guia apenas por estas últimas, "sempre fomos o que somos e somos o que sempre seremos", porque as sensações não mudam e não podem se agruparem sucessivamente gerando novas sensações, além de esvanecerem-se após o fim da relação corpo-exterioridade. Como, ao $78 \quad$ Ao afirmar que as ideias formam um mundo à parte, no interior do indivíduo, Constant revela, por outro lado, uma influência idealista sobre seu pensamento (BARROSO, 2011, p. 53).

79 Tradução minha de "Dans la comparaison de l'influence des sensations proprement dites, et de ce que nous nommons idées, se trouve la solution du problème de la perfectibilité humaine.". 
observar a História, Constant concebe uma progressiva melhoria da realidade, ele afirma então que o homem se guia, em maior ou menor grau, pelas ideias. A forma como elas se aperfeiçoam traduz-se na combinação de uma com as outras, em um processo cognitivo lento e constante capaz de gerar ideias cada vez melhores. Para Constant, "mesmo que nossas ideias atuais sejam falsas, elas trazem, em si, um germe de combinações sempre novas, de retificações mais ou menos imediatas, mas infalíveis e de progressão ininterrupta" (CONSTANT, 1829, p. 392-393) ${ }^{80}$.

Constant avalia que "existe, na natureza humana, uma disposição que lhe dá perpetuamente a força para imolar o presente ao futuro e, consequentemente, a sensação à ideia" (CONSTANT, 1829, p. 394) ${ }^{81}$. Ele desenvolve, então, a noção de sacrifício como causa do domínio das ideias sobre as sensações e, a partir disso, de uma melhoria nas realidades humanas. Para o francês, a capacidade humana de renunciar a sensações momentâneas, tendo em vista a lembrança de uma sensação, uma ideia, constitui o ato de se sacrificar por um bem maior no futuro. Num primeiro momento, Constant utiliza-se da mitologia grega para ilustrar seu raciocínio: Hero, uma sacerdotisa de Afrodite, vivia em uma torre à margem do estreito de Helesponto. Leandro, apaixonando-se por ela, atravessava o canal a nado todas as noites para encontrá-la até que, numa noite de tempestade, afoga-se e morre. O mito constituiria um exemplo da tendência ao sacrifício intrínseca ao homem. Segundo ele,

quando Leandro atravessava o mar a nado para se reunir com Hero, ele suportou uma dor real na esperança de um prazer futuro; e, de fato, sacrificou uma sensação a uma ideia. Esses sacrifícios se repetem a cada instante na vida de cada um de nós. E os homens mais egoístas, mais voluptuosos se submetem a isso tão frequentemente, tão constantemente, melhor

80 Tradução minha de "nous avons été de tout temps ce que nous sommes, nous sommes ce que nous serons toujours. [...] Lors même que nos idées actuelles seraient fausses, telles portent en elles un germe de combinaisons toujours nouvelles, de rectifications plus ou moins promptes, mais infaillibles, et de progression non interrompue".

81 Tradução minha de "existe dans la nature humaine une disposition qui lui donne perpétuellement la force d'immoler Je présent à l'avenir et par conséquentila sensation à l'idée". 
dizendo, quanto os mais desinteressados e generosos (CONSTANT, 1829, p. 394) ${ }^{82}$.

E, visando a convencer seu leitor, Constant utiliza-se de exemplos corriqueiros para demostrar que a noção de sacrifício, o domínio da ideia sobre a sensação, é comum a todos os homens:

essa operação é a mesma no trabalhador laborioso que se esgota com trabalho para alimentar sua família; no avarento que suporta o frio e a fome para manter seu ouro; no amante que enfrenta o cansaço e o mau tempo da noite para enternecer a sua amante; no ambicioso que repele o sono ou que negligencia uma ferida para escravizar seu país; e no generoso cidadão que vigia, luta e sofre para salvá-lo. Existe, em todos, a possibilidade de sacrifício; em todos, em uma palavra, dominação sobre as sensações pelas ideias (CONSTANT, 1829 , p. $394-395)^{83}$.

A noção de sacrifício extrapola os limites do indivíduo e chega aos objetos exteriores. Para Constant, "a faculdade de se sacrificar é entendida como vontade e o primeiro 'meio' sobre o qual ela atua é o próprio corpo do indivíduo, seus órgãos e membros", em seguida "são dominados os objetos exteriores, que se tornam ferramentas de auxílio, o que possibilita ao homem ultrapassar os limites impostos por sua constituição física e, ao mesmo tempo, propicia as mudanças do mundo ao seu derredor". Há, para Constant, portanto, duas formas de perfectibilidade: aquela interior, que é o avanço das ideias no indiví-

\footnotetext{
82 Tradução minha de "Lorsque Léandre traversait la mer à la nage pour aller rejoindre Héro, il supportait une douleur réelle dans l'espérance d'un plaisir futur ; et dans le fait, il sacrifiait une sensation à une idée. Ces sacrifices se répètent à chaque instant dans la vie de chacun de nous; et les hommes les plus égoïstes, les plus sensuels s'y soumettent aussi fréquemment, aussi constamment, pour mieux dire, que les plus désintéressés et les plus généreux".

83 Tradução minha de "Lopération est la même dans l'ouvrier laborieux qui s'épuise de travail pour nourrir sa famille, dans l'avare qui supporte le froid et la faim pour conserver son or, dans l'amant qui brave la fatigue et l'intempérie des nuits pour attendrir sa maîtresse, dans l'ambitieux qui repousse le sommeil ou néglige une blessure pour asservir sa patrie, dans le citoyen généreux qui veille, combat et souffre pour la sauver. Il y a dans tous, possibilité de sacrifice; dans tous, en un mot, domination sur les sensations par les idées".
} 
duo, da moralidade ${ }^{84}$; e há aquela exterior, que é o progresso científico e técnico ao longo da História, também originado da faculdade de sacrificar-se (BARROSO, 2011, p. 55) ${ }^{85}$.

Nada obstante, o processo de aperfeiçoamento não é uma obrigação para os homens, mas uma tendência. Existe, certamente, um arranjo da natureza que facilita a perfectibilidade, a saber, a propensão do homem em sacrificar as sensações às ideias, no entanto, tal direcionamento não é absoluto. As quatro revoluções históricas (que se verão mais adiante) não são a causa do aperfeiçoamento do homem, mas justamente os sintomas, a ocasião propícia desse progresso (CONSTANT, 1829, p. 406-407). Cumpre ressaltar que Constant, aqui, não se alinha ao discurso iluminista de que o homem "deve emancipar-se da sujeição dos sentidos e se conduzir pela luz da razão" (CONSTANT, 1829, p. 393) ${ }^{86}$. Pelo contrário, ele afirma que "não são mais suas sensações que devem ser derrotadas, é apenas sua razão que precisa ser aperfeiçoada. Não se trata de criar nele uma força estrangeira, mas de desenvolver e ampliar uma força que lhe é própria" (CONSTANT, 1829, p. 396) ${ }^{87}$. O indivíduo, dessa forma, só pode formar ideias a partir de se mesmo, o que, em certa medida, se alinha com o ideal iluminista a partir do qual somente o individuo racional pode garantir os ideais de paz, liberdade, igualdade e felicidade (MAYOS

$84 \quad$ Inobstante o uso que Constant faz da palavra moral (morale, no francês), o termo deve ser entendido no sentido etimológico original da palavra ethos, isto é, como o campo de abrangência de todos os aspectos da práxis social seja em suas manifestações histórico-empíricas, seja em sua estrutura lógica, a qual se insere no estudo da Filosofia, conforme o conceito dado por Lima Vaz (1999, p. 17).

85 Complementa Faria (2013, p. 67-68) dizendo que "não existe, para Constant, renúncia propriamente moral se não existe sacrifício. A renúncia moral é um ato puramente de sacrifício. Há mesmo uma identificação entre estética e ética para Constant, no que tange à sua ideia de sacrifício como motor das ações morais".

86 Tradução minha de "l'homme doit s'affranchir de la sujétion des sens et se conduire par les lumières de la raison".

87 Tradução minha de "ce ne sont plus ses sensations qu'il faut vaincre, c'est uniquement sa raison qu'il faut perfectionner. Il n'est pi us question de créer en lui une force étrangère, mais de développer et d'étendre une force qui lui est propre". 
SOLSONA, 2004, p. 364), apesar de se distanciar desse mesmo ideal ao recusar descartar as sensações.

Tal como Kant, Constant reconhece a possibilidade humana de extrapolar os limites do sensível e agir, se não conforme a razão, conforme as ideias. Nesse sentido, para o prussiano, os homens podem agir tanto de forma puramente instintiva quanto de forma racional. Não se pode, entretanto, afirmar que a atuação humana será determinada de forma absoluta pelo mundo sensível ou pelo inteligível. Há, contudo, um arranjo da natureza que permite o desenvolvimento racional do homem: a sociabilidade insociável, isto é, o antagonismo dos indivíduos que se associam e que leva ao estabelecimento de uma ordem jurídica garantidora do direito peremptório e que reflete, em maior ou menor grau, a razão e seu imperativo de universalidade (KANT, 2002, p. 25; KANT, 2003, p. 76). Ambos são otimistas. Constant crê que o homem, influenciado pelas sensações e/ou pelas ideias, inegavelmente se guiará por estas últimas e, munido do desejo de sacrificar-se, tornará as ideias os móbiles de sua ação. Para Kant, "o homem já traz dentro de si a disposição para ser moral" (SALGADO, 2008, p. 148).

O dirigir-se pelas ideias, e não pelas sensações, é intrínseco ao homem. Para Constant este processo "não vai mudar, ele não pode mudar. Somente, como acabamos de dizer, se o império é das sensações, a espécie humana será estacionária; se o império é das ideias, será progressiva" (CONSTANT, 1829, p. 393) $)^{88}$.

\section{A perfectibilidade da espécie humana}

O sistema de evolução das ideias é uma forma de explicar a ligação entre indivíduo e sociedade e entre passado, presente e futuro. Em outros termos, "a capacidade de se aperfeiçoar também seria a garantia de que os desígnios da ordem social não seriam simples combinações do acaso, ligando as gerações entre si" (BARROSO, 2011, p. 52). O processo de perfec-

$88 \quad$ Tradução minha de "n'en changera pas, il n'en peut changer; seulement, comme nous venons de le dire, si l'empire est aux sensations, l'espèce humaine sera stationnaire; si l'empire est-aux idées, elle sera progressive". 
tibilidade que corre em relação à moral e ao domínio dos bens exteriores é individual. Ele, no entanto, se comunica à espécie como um todo. A relação que aqui se estabelece entre indivíduo também é um dos pontos essenciais para a compreensão da Filosofia da História de Constant.

Constant considera que verdades (obtidas através da combinação das sensações no ato de conhecer) repetidas de forma constante e por todos os membros da sociedade tornam-se o que ele denomina de verdades evidentes. A verdade evidente é apenas uma ideia, cuja familiaridade nos leva imediatamente ao ato intelectual que deu origem a ela sem que tenhamos necessariamente que repeti-lo. Por isso, ela alcança um assentimento imediato de todos. Para ilustrar uma verdade evidente moral, ele se utiliza de uma verdade evidente matemática: a operação dois mais dois é igual a quatro nos é tão familiar que automaticamente a realizamos. Não compreendemos com a mesma rapidez, contudo, que sessenta e nove mais cento e oitenta e sete é igual a duzentos e cinquenta e seis. Ademais, isso não prova que a primeira operação é mais ou menos incontestável que a segunda, mas tão somente que existem raciocínios (combinações entre sensações e/ou ideias) que são reconhecidos, pela força do hábito, instantaneamente, por nós. No campo da moral e da razão, essas verdades evidentes dão origem a uma moralidade que é comum a todos os indivíduos. Quando tal moral se sedimenta, o indivíduo parte seu raciocínio do ponto onde a associação o pôs. Ocorre, assim, entre as gerações, o processo de perfectibilidade. A História, então - por uma sucessão de impressões e combinações e por repetições desses processos -, progride. Segundo Constant,

da união dessas verdades, adotadas por todos os indivíduos, e do hábito dos sacrifícios que elas lhes impõem, estabelece-se uma razão, uma moralidade comum a todos é estabelecida, cujos princípios, recebidos sem discussão, não são postos em dúvida. $\mathrm{O}$ indivíduo, então, não é mais obrigado a repetir uma tarefa concluída antes dele; ele parte, não do ponto em que sua inexperiência individual o colocaria, mas do ponto 
onde a experiência da associação o colocou (CONSTANT, 1829 , p. $399-400)^{89}$.

Assim, ao mesmo tempo em que o indivíduo contribui para essa moral, a sociedade também exerce influência sobre ele, pois lhe dá acesso a todo o conhecimento produzido nas gerações anteriores a sua. Assim, "da união dessas verdades com a capacidade de se sacrificar pelas ideias surge uma razão, que estabelece uma moral social - que é a associação das experiências de indivíduo e sociedade" (BARROSO, 2011, p. 55) ${ }^{90}$.

Kant, de maneira semelhante, também adota a perspectiva de que o aperfeiçoamento da humanidade dá-se em toda a espécie, e não apenas no indivíduo. Diz o prussiano que

no homem (como única criatura racional sobre a terra), as disposições naturais que visam o uso da razão devem desenvolver-se integralmente só na espécie, e não no indivíduo. [...] Se a natureza estabeleceu apenas um breve prazo à sua vida (como realmente acontece), ela necessita de uma série talvez incontável de gerações, das quais uma transmite à outra os seus conhecimentos para que, finalmente, o seu germe ínsito na nossa espécie alcance aquele estágio de desenvolvimento, que é plenamente adequado à sua intenção" [grifos no original] (KANT, 2002, p. 23-24).

$89 \quad$ Tradução minha de "De la réunion des ces vérités, adoptées par tous les individus, et de l'habitude des sacrifices que ces vérités leur imposent, se forme une raison s'établit une morale commune à tous, dont les principes, reçus sans discussion, ne se mettent plus en doute. Alors l'individu n'est plus obligé de recommencer une tâche remplie avant lui; il part, non du point où le placerait son inexpérience individuelle, mais du point où l'a porté l'expérience de l'association".

90 Sem abandonar a defesa de princípios universais (nesse caso a liberdade individual de pensamento) Constant complementa que a liberdade política é o melhor caminho institucional que permite o exercício do pensamento por todos. Para ele "a melhor parte da nossa natureza, essa nobre inquietude que nos persegue e atormenta, esse ardor de entender nossas luzes e de desenvolver nossas faculdade, não é somente para a felicidade, é para o aperfeiçoamento que nosso destino chama. E a liberdade política é a mais poderosa, o mais energético meio de aperfeiçoamento que o céu nos deu. A liberdade política, submetendo a todos os cidadãos, sem exceção, o exame e o estudo dos seus interesses mais sagrados, amplia o seu espírito, enobrece seus pensamentos, estabelece entre todos eles uma espécie de igualdade intelectual que faz a glória e o poder de um povo" (CONSTANT, 2015, p. 101). 
Para Kant, se há uma disposição da natureza para que o homem aja livremente haverá também uma tendência para o melhoramento das instituições políticas, isto é, se o homem age cada vez mais conforme a razão, os princípios de política também serão progressivamente conforme a ela (KANT, 2002, p. 18-19). Por outro lado, como se verá mais adiante, para Kant o aperfeiçoamento do sistema político não necessariamente implica o aperfeiçoamento moral humano, dada a diferença de motivação que existe entre um ato moral e um ato político-jurídico.

\section{Evidências empíricas da perfectibilidade}

A prova da perfectibilidade da espécie humana situa-se na própria História. Constant enumera quatro revoluções que, para ele, seriam a evidência de que há um progresso moral da humanidade em curso. São elas: a abolição da teocracia, a abolição da escravidão civil (com o advento do Cristianismo e da Idade Média), a abolição das relações de servidão do sistema feudal (a partir da centralização do poder nas mãos dos reis e do surgimento da monarquia absoluta) e, por fim, a abolição dos privilégios de nobreza (processo que se desencadeia no século XVIII com o surgimento dos Estados de Direito). Para o francês, cada passo ocorrido nesse trajeto histórico foi sem retorno. E ainda pergunta ao leitor: "não é então evidente que tal progressão é uma lei da natureza, e que cada uma dessas épocas portavam em si os elementos das épocas que deveriam as substituir?" (CONSTANT, 1829, 405) ${ }^{91}$.

O processo de perfectibilidade é de cunho moralizante. A espécie humana, passo após passo, é moralizada, pois todas as revoluções dizem respeito às relações dos homens entre si e às formas segundo cada qual deva ser tratado. Segundo Barroso (2011, p. 56), "estas revoluções são caracterizadas mais pela negação de um estado do que pela afirmação do posterior, que é sempre transitório. [...] Seriam [...] sinais que apontariam

$91 \quad$ Tradução minha de "N'est-il donc pas évident qu'une progression pareille est une loi de la nature, et que chacune de ces époques portait en elle-même les élémens des époques qui devaient la remplacer?". 
para o restabelecimento da igualdade natural, finalidade última da perfectibilidade humana".

Kant, nessa mesma linha, também considera que é necessário encontrar um acontecimento político que prove o progresso da humanidade. Tal como Constant, ele encontra essa prova na Revolução Francesa, momento no qual a comunidade política se dá uma constituição e a torna (ou ao menos tenta torná-la) republicana (SALGADO, 1995, p. 287).

A última das revoluções (a abolição dos privilégios de nobreza) inaugura a era das convenções legais, isto é, do Estado de Direito. Para Constant, as leis são "uma espécie de razão comum e consensual, o produto médio de todas as razões individuais" As leis do seu tempo (e, considerando que a contemporaneidade já se inicia quando Constant escreve a quase totalidade de sua obra, do nosso tempo) são relativas. "Não são coisas naturais ou imutáveis". Ao contrário, são "passíveis de mudança, criadas para substituir verdades ainda pouco conhecidas, satisfazer necessidades temporárias e, portanto, passíveis de serem emendadas, aperfeiçoadas e, especialmente, restritas à medida que essas verdades são descobertas ou quando essas necessidades mudam". E, além disso, deixando Constant transparecer uma visão próxima ao positivismo, elas existem por si mesmas, sem estarem lastreadas em nenhum tipo de crença religiosa ou superstição (CONSTANT, 1829, p. 412-413) ${ }^{92}$.

Kant, ao observar a História da Europa afirma que se pode descobrir "um curso regular da melhoria da constituição estatal na nossa parte do mundo (que, provavelmente, algum dia dará leis a todas as outras)". Uma das provas da escala ascendente da História humana também é o progressivo melhoramento da comunidade política, isto é, do aparato gover-

92 Tradução minha de "[...] une sorte de raison commune et convenue, le produit moyen de toutes les raisons individuelles. [...] ne sont pas des choses naturelles ou immuables. [...] susceptibles de changement, créées pour remplacer des vérités encore peu connues, pour subvenir à des besoins momentanés, et devant par conséquent être amendées, perfectionnées, et surtout restreintes, à mesure que ces vérités se découvrent, ou que ces besoins se modifient". 
namental e das relações dos homens entre si, melhor dizendo, do Direito (KANT, 2002, p. 35-37).

Por outro lado, Constant destoa de Kant. O francês considera que há uma relação necessária entre política e moral. Se as ideias são os móveis da ação política, ao se aperfeiçoarem, aperfeiçoa-se também o sistema político. Kant, ao contrário, considera que a obediência à lei e ao sistema coercitivo do Direito não prescinde o dever per si. Assim, um indivíduo pode obedecer às leis por causas externas, como medo, hábito etc. A evolução do sistema político, então, não é atrelada à evolução da moral, que necessita de uma vontade livre e não influenciada pelo sensível. Segundo Alves (1994, p. 170), no sistema kantiano,

a constituição de uma comunidade de seres livres que se determinariam apenas segundo leis da virtude, constituição que deve ser considerada como o interesse supremo da razão, não é, assim, plasmável na ordem política. Nenhuma forma de organização jurídico-política pode engendrar mecanicamente o advento da moralidade e não há estratégia política possível para a promoção da regeneração moral dos indivíduos.

As condições morais atingidas pela humanidade enquanto se aperfeiçoa são irreversíveis. No que tange à perfectibilidade externa (melhoramento científico e técnico), por óbvio, não há regresso. Constant utiliza como exemplo a escravidão: nem mesmo o aristocrata mais inveterado de sua época sugeriu seu retorno, mesmo que, para Aristóteles, por exemplo, a vida em sociedade fosse pensada como impossível sem ela (CONSTANT 1829, 400). Nesse sentido, segundo Ghelere (2008, p. 39-40),

o universo moral e mental, pensa Constant, o modo de pensar e as concepções do que é viver em sociedade mudam de forma irreversível. A tese da irreversibilidade histórica se sustenta, então, na tendência para a perfectibilidade, que, por sua vez, é o lugar das condições morais que não podem ser recuperadas. [...] É como tentar reviver a inocência perdida na infância. Por isso, ao comparar os antigos com os modernos, Benjamin Constant sustenta, para além (e por causa) das mudanças nas condições materiais da existência, uma análise psicológica, julgando em cada aspecto, qual é a melhor época.

Ao comparar a forma como os antigos concebiam a liberdade (total liberdade política e um estrito controle sobre a 
liberdade individual) com como os modernos o fazem (liberdade política restrita e pouco ou nenhum controle sobre a liberdade individual), Constant considera que a ignorância dessa irreversibilidade das condições morais gerou a violência na Revolução Francesa. Para ele, é a tentativa de restaurar condições morais e psicológicas dos antigos na modernidade que motivou os revolucionários a instaurarem o Terror na década de 1790 (CONSTANT, 2015, p. 75).

Contrariando o espírito iluminista no qual foi formado, Constant não vê, então, o passado com um olhar crítico: a evolução moral do homem para ele permite que determinados institutos existam ou deixem de existir. Nada é ruim por natureza, mas a aplicação desmedida de qualquer instituição em um tempo que lhe seja alheio é o que a torna abusiva e má. Assim,

o que foi melhor ou pior em seu momento histórico, aquilo que pode ter sido considerado adequado no seu tempo, transforma-se em algo negativo quando se pretende aplicá-lo mecânica e mimeticamente a uma realidade que já não tem correspondência. Nas referências de Constant ao passado jamais há uma avaliação negativa dos povos ou sociedades que nos precederam. [...] Simplesmente existiram em outros tempos, com outros costumes, outras necessidades e outros meios para satisfazê-las (SÁ, 2012, p. 192).

Para o francês, algumas causas materiais podem, de fato, criar a aparência de que há um retrocesso na moralidade humana. O fim dessas causas, no entanto, faz com que a sociedade retorne ao estágio anterior. Nota-se aqui uma forma um tanto quanto primitiva de se pensar a História dialeticamente: se por um lado, ela não é cíclica, por outro, há uma constante ascendência que, às vezes, recua, mas sempre retorna a um ponto mais elevado, como se tal ponto fosse uma negação da negação. Assim, afirma Constant que "os excessos da revolução perverteram os indivíduos, mas não substituíram o sistema moral que existia por um sistema de moralidade menos perfeito" (CONSTANT, 1829, p. 401) ${ }^{93}$.

93 Tradução minha de "les excès de la révolution ont perverti des individus, mais non substitué au système de morale qui existait un système de morale moins parfait". 
O processo de aperfeiçoamento é, acima de tudo, coletivo, ocorre nos indivíduos, mas, sempre, se comunica à espécie. Constant diz que aqueles que não reconhecem esse trajeto ascendente da humanidade consideram apenas algumas sociedades e alguns indivíduos em suas análises e tendem a pensar que a História é um eterno ciclo que oscila entre luzes e obscurantismo. É necessário considerar a humanidade como um todo, e não apenas parcialmente (CONSTANT, 1829, p. 403). Hofmann (2009, p. 261) nos lembra de que a Filosofia da História de Constant é incompatível com uma visão míope: é preciso se afastar do curso dos acontecimentos históricos para enxergar uma lógica intrínseca a eles.

Constant adota tal percepção devido ao momento histórico no qual se situa e podemos sustentar que a perspect6iva histórica adotada por ele é quase apologética. Além de tentar compreender todos os acontecimentos históricos ao seu redor (e, de fato, as quatro revoluções são dados significantes da história da França e da Europa), tenta "assimilar os ganhos históricos da razão sem abalar, de forma abrupta e desnecessária, as estruturas sociais vigentes e alertar para os inconvenientes revolucionários" (FARIA, 2013, p. 84).

O que faz, então, uma instituição surgir ou desaparecer ao longo da História e tornar-se mais ou menos anacrônica em relação a uma determinada era? Responde Constant que é a própria natureza a responsável por fazer um instituto perecer ou não. Nesse sentido, a natureza agiria através da constante descoberta de novas verdades a partir das impressões que o mundo externo causa no corpo. Mesmo que uma instituição seja abusiva, o abuso, de alguma forma misteriosa e que só será compreendida no futuro, é útil para a sociedade naquele determinado momento em que existe. À medida que a humanidade vai descobrindo novas verdades, a utilidade dessas instituições vai também variando (CONSTANT, 1829, p. 410).

Dessa forma, para Constant, existem sistemas políticos que são autorizados ou não pelo seu tempo. É o progresso moral da humanidade que dirá se determinada forma de civilização poderá existir ou não em determinada era. Assim, a 
liberdade moderna, por exemplo, só é possível na e para a Modernidade. A Natureza e a História possuem dupla autoridade na ideia de progresso de Constant. A última é a trilha na qual a perfectibilidade se desenvolve e, ao mesmo tempo, prova desse processo. A primeira é a força que autoriza (pelas combinações infinitas de sensações que, por sua vez, são influenciadas pelo clima, vegetação, proximidade com outros povos, pela estrutura social já existente etc) o progresso ocorrer ou não (GHELERE, 2008, p. 13).

Nesse ponto, nota-se uma aproximação do pensamento constantiano ao pensamento romântico. Como determinadas comunidades políticas só podem existir se houver um progresso moral humano que propicie sua existência, o passado possui um valor autônomo, mesmo que esse valor se insira em um trajeto de progressivo desenvolvimento da humanidade. Assim, os românticos, bem como Constant, "sentiam real admiração e simpatia pelos tempos pretéritos - isso porque eles discerniam nas realizações daqueles tempos o espírito de seu próprio tempo. Tratava-se de verdadeira herança apropriada" (FARIA, 2013, p. 75-76). Ainda segundo Faria (2013, p. 85),

Constant não nega, com essas afirmativas, que as ideias que foram formuladas no passado possam ser aproveitadas pelas sociedades modernas. Ele enfatiza, todavia, que aquelas ideias têm o seu devido lugar histórico, e que, para continuarem a serem utilizadas, elas devem corresponder ao modo de ser do homem contemporâneo.

Constant discorda daqueles que defendem a existência de determinada instituições unicamente porque são tradições. $\mathrm{Na}$ verdade, ele considera que instituições sancionadas pelo tempo, na maior parte das vezes, não possuem nenhum motivo racional para existirem e permanecem justamente porque são legitimadas pelo tempo. Assim, "qualquer defesa das instituições existentes deve levar em conta o estágio de desenvolvimento humano, o que significava que as instituições que eram comprovadamente benéficas no passado poderiam não durar [no presente]" (VINCENT, 2011, p. 123) ${ }^{94}$.

$94 \quad$ Tradução minha de "He argued that the human species was progressive, and that any defense of extant institutions must take into account 


\section{Conclusões}

O destino da espécie humana, o fim para o qual ela se aperfeiçoa é a igualdade. Para Constant (1829, 407), as "quatro revoluções [...] são todas passos para a restauração da igualdade natural. A perfectibilidade da espécie humana nada mais é do que a tendência à igualdade" 95 .

Segundo o francês, somente a igualdade é conforme a verdade das coisas, ou seja, conforme as relações originárias das coisas entre si e com os homens. A desigualdade é o elemento que constitui a injustiça. Para Constant, todas as formas de injustiça, das mais particulares àquelas que impactam uma Nação inteira, fundam-se na desigualdade. Toda vez que o homem raciocina e exerce sua faculdade de sacrifício, ele toma a igualdade como seu ponto de partida, "pois ele adquire a convicção de que não deve fazer aos outros o que não desejasse que lhe fizessem, isto é, que deve tratar os outros como seus iguais e que tem o direito de não sofrer dos outros o que eles não gostariam de sofrer dele; isto é, que os outros devem tratá-lo como seu igual" (CONSTANT, 1829, p. 407) ${ }^{96}$. Nesse sentido, "sempre que uma verdade é descoberta, e a verdade tende por sua natureza a ser descoberta, o homem se aproxima da igualdade" (CONSTANT, 1829, p. 408) ${ }^{97}$.

Para Todorov, a igualdade constantiana é um valor que escapa de qualquer forma de historicismo: ela constitui a meta e a direção da História, é um valor trans-histórico. Constant, acreditando que ela se move em certa direção - mesmo que, em

the stage of human development, which meant that institutions that were demonstrably beneficial in the past might not endure".

95 Tradução minha de "Ces quatre révolutions [...] sont autant de pas vers le rétablissement de l'égalité naturelle. La perfectibilité de l'espèce humaine n'est autre chose, que la tendance vers l'égalité".

96 Tradução minha de "car il acquiert la conviction qu'il ne doit pas faire aux autres ce qu'il ne voudrait pas qu'on lui fit, c'est-à-dire qu'il doit traiter les autres comme ses égaux, et qu'il a le droit de ne pas souffrir des autres ce qu'ils ne voudraient pas souffrir de lui ; c'est-à-dire que les autres doivent le traiter comme leur égal".

97 Tradução minha de "toutes les fois qu'une vérité se découvre, et la vérité tend par sa nature à se découvrir, l'homme se rapproche de l'égalité". 
particular, ela pareça regredir ou mover-se como um pêndulo -, propõe a igualdade como um valor universal e como uma categoria do espírito. Na verdade, Constant propõe algo mais: a igualdade é parte integrante da realidade. Nesse sentido,

a humanidade, em sua evolução, segue o caminho para o progresso, isto é, para a reconciliação com a igualdade; o que também significa que o pensamento de Constant, em termos de valores, longe de diluir todos os absolutos na História, submete a própria História ao seu Sistema ${ }^{98}$ (TODOROV, 1999, p. 68).

A liberdade, por si só, é um valor histórico (que se faz presente na Modernidade e na Antiguidade de diferentes formas e com diferentes interações com o corpo social), mas constitui o meio pelo qual os homens chegam à igualdade. Somente a liberdade individual (o triunfo da individualidade) é o caminho para os homens, aperfeiçoando-se moralmente e pensando livremente, chegarem à igualdade natural entre todos (TODOROV, 1999, p. 67).

Kant, por sua vez, tomando a liberdade como a pedra de toque segundo a qual a História pode ser avaliada, isto é, como seu fio condutor, considera que manifestações empíricas da liberdade podem ser subsumidas na própria ideia de liberdade. (SALGADO, 2008, p. 160-161). Constant considera que a igualdade empírica, manifestada, e cada vez mais evidentemente, na História, deve ser também subsumida numa ideia de igualdade.

Em Kant, o fim da História é a paz perpétua, momento no qual o homem, livre, realizar-se-á moralmente e alcançará a felicidade (SALGADO, 1995, p. 327). Em Constant, o fim da História é o reestabelecimento da igualdade que naturalmente existe entre os homens e que tem origem no sentimento inato de justiça. Em ambos, o coroamento da História é uma comunidade política simultaneamente livre e igualitária. Um deles utiliza-se da liberdade para interpretar a marcha humana rumo a esse ideal. O outro, da igualdade. Esses pontos de vista, con98

Tradução minha de "Humanity in its evolution follows the road to progress, that is, to reconciliation with equality; which also means that Constant's thought, in terms of values, far from diluting all absolutes in history, submits history to the system". 
tudo, não se excluem: a humanidade kantiana livre é também igual, pois todos são igualmente súditos e legisladores; por outro lado, a humanidade igualitária constantiana é livre, pois somente a liberdade individual e o livre pensamento (o uso público da razão, em Kant) dão ao homem o ambiente propício para desenvolver suas ideias e, a partir dai, formular uma moral social comum a todos.

O pensamento kantiano assume que a Ciência da História não deve descrever como a consciência, a vontade livre, o dever mudam o curso da História a partir da experiência de cada homem. Na verdade, para Kant, as intenções dos homens são egoístas e tendem para a realização do seu próprio interesse. É a natureza, através da noção de sociabilidade insociável, que garante, a longo prazo, o progresso da humanidade (ALVES, 1994, p. 152-153). Mesmo que esse último aspecto também esteja presente no pensamento de Constant (isto é, o progresso como um dado da natureza), ele considera que é o indivíduo, querendo sacrificar-se e concebendo a ideia de justiça, quem faz a História mover-se. Há, de fato, uma disposição da Natureza em fazer a humanidade evoluir, mas essa disposição se realiza no indivíduo que se sacrifica e que, aos poucos, faz transparecer a noção de justiça. Em Kant, são os choques entre os interesses particulares - os quais geram a necessidade do estabelecimento de uma ordem coativa que se aproxima da Razão - que dão origem a patamares cada vez mais altos de progresso humano (ALVES, 1994, p. 161).

Nada obstante, Constant ainda pertence a seu tempo histórico. A igualdade não deve ser entendida materialmente. Ao contrário, a igualdade constantiana é a igualdade de meios, de possibilidades de se desenvolver, igualdade de liberdade individual para "não ser submetido senão às leis, de não poder ser preso, detido, condenado à morte nem maltratado de maneira alguma pela só vontade arbitrária de um ou de vários indivíduos" e para "preencher seus dias e suas horas da maneira mais conforme às suas inclinações, às suas fantasias" (CONSTANT, 2015, p. 77-78; BARROSO, 2011, p. 56-57). Para Constant, os homens não são moralmente iguais, mas o sentimento de jus- 
tiça, de correção da desigualdade, é inerente a todos. Ele visa, "em condições iguais, que cada um deva ser tratado da mesma maneira. Conforme frisa Todorov, este sentimento é inato e universal, ele é um efeito natural da reciprocidade das relações" (BARROSO, 2011, p. 56-57).

Se a igualdade constitui um valor universal, podemos, então, julgar a História a partir dela. Podemos julgar o passado ao invés de apenas recontá-lo às gerações seguintes (TODOROV, 1999, p. 67), o que o reaproxima da forma ilustrada de conceber a realidade a partir de um ponto de vista também considerado universal. Podemos, por fim, afirmar que a humanidade aperfeiçoa-se com o passar do tempo. E talvez seja daqui que Benjamin Constant extrai seu otimismo com relação ao gênero humano: olhando a História de onde se situava, ele podia observar os avanços morais ocorridos no passado e aqueles que ocorreram ainda durante sua juventude na Revolução Francesa. Seria impossível que ele não sentisse o entusiasmo que outros de sua época também sentiram ao verem a História se descortinando diante de seus olhos, tal como o próprio Kant, e não julgasse que o homem progredia em relação ao passado.

\section{Referências:}

ALVES, Pedro M. S. Do primado prático à Filosofia da História. In: FERREIRA, Manuel J. Carmo e SANTOS, Leonel Ribeiro dos (orgs.). Religião, História e Razão da Aufklärung ao Romantismo. Lisboa: Edições Colibri, 1994, p. 147-172.

BARROS, Roque Spencer Maciel de. Introdução à Filosofia Liberal. São Paulo: Editora USP, 1971

BARROSO, Marco Antônio. Constant de Rebecque e a perfectibilidade humana. In: Sacrilegens, Juiz de Fora, v.8, n.1, dez/2011, p. 49-60.

CONSTANT, Benjamin. A liberdade dos antigos comparada à dos modernos. Tradução de Emerson Garcia. São Paulo: Atlas, 2015, p. 9-14.

CONSTANT, Benjamin. Da força do governo atual da França e da necessidade de apoiá-lo. Tradução de Josemar Machado de Oliveira. In: Revista de História da Universidade de São Paulo, n.145, 2001, p. 181-230. 
CONSTANT, Benjamin. De la perfectibilité de l'espèce humaine. In: CONSTANT, Benjamin. Mélanges de Littérature et de politique. Paris: Pichon et Didier, 1829, p. 387-415.

CONSTANT, Benjamin. Del espíritu de conquista y de la usurpación en relación con la civilización europea. Traducción de Anna Portuondo Pérez. Madrid: Tecnos, 2008.

CONSTANT, Benjamin. Princípios de Política Aplicáveis a Todos os Governos. Tradução de Joubert de Oliveira Brízida. Rio de Janeiro: Topbooks, 2007.

FARIA, Marco Antônio Barroso. Benjamin Constant de Rebecque entre o iluminismo e o romantismo: uma teoria crítica pra a compreensão do sentimento religioso. Universidade Federal de Juiz de Fora, 2013 [tese de doutorado].

GHELERE, Gabriela Doll. A liberdade individual para Benjamin Constant. Universidade de São Paulo, 2008 [dissertação de mestrado].

HOFMANN, Etienne. The Theory of the Perfectibility of the Human Race. In: ROSENBLATT, Helena. The Cambridge Companion to Constant. Cambridge: Cambridge University Press, 2009, p. 248-271.

HUME, David. Tratado da natureza humana: uma tentativa de introduzir o método experimental de raciocínio nos assuntos morais. Tradução de Débora Danowski. São Paulo: Editora UNESP, 2009.

KANT, Immanuel. A Metafísica dos Costumes. Tradução de Edson Bini. Bauru: EDIPRO, 2003.

KANT, Immanuel. Ideia de uma História universal com um propósito cosmopolita. In: KANT, Immanuel. A paz perpétua e outros opúsculos. Tradução de Artur Morão. Lisboa: Edições 70, 2002, p. 21-38.

KANT, Immanuel. Resposta à pergunta: que é o Iluminismo? In: KANT, Immanuel. A paz perpétua e outros opúsculos. Tradução de Artur Morão. Lisboa: Edições 70, 2002, p. 11-20.

LIMA VAZ, Henrique Cláudio de. Escritos de Filosofia IV: Introdução à Ética Filosófica I. São Paulo: Loyola, 1999.

LOCKE, John. Ensaio sobre o entendimento humano. Vol 1. Introdução, notas e coordenação da tradução de Eduardo Abranches de Soveral. Revisão da tradução de Gualter Cunha e Ana Luísa Amaral. Braga: Fundação Calouste Gulbenkian, 2014.

MAYOS SOLSONA, Gonçal. Ilustración y Romanticismo: introducción a la polémica entre Kant e Herder. Barcelona: Herder Editorial, 2004.

PASSMORE, John Arthur. The perfectibility of man. Indianapolis: Liberty Fund, 2000.

ROSANVALLON, Pierre. El momento Guizot. El liberalismo doctrinario entre la Restauración y la Revolución de 1848. Traducción de Hernán M. Díaz. Ciudad Autónoma de buenos Aires: Biblos, 2015. 
ROSENBLATT, Helena. Eclipses and Revivals: Constant's Reception in France and America 1830-2007. In: ROSENBLATT, Helena. The Cambridge Companion to Constant. Cambridge: Cambridge University Press, 2009.

SÁ, Fernando. Opinião pública: um conceito em disputa. ALCEU: Revista do Departamento de comunicação Social da PUC-Rio. Vol. 13, n. 25, 2012, p. 185-199.

SALGADO, Joaquim Carlos. A ideia de Justiça em Kant: seu fundamento na liberdade e na igualdade. Belo Horizonte: Editora UFMG, 1995.

SALGADO, Karine. A paz perpétua de Kant: atualidade e efetivação. Belo Horizonte: Mandamentos, Faculdade de Ciências Humanas/ FUMEC, 2008.

TODOROV, Tzvetan. A passion for democracy: Benjamin Constant. Translated from French by Alice Seberry. New York: Algora Publishing, 1999.

VINCENT, K. Steven. Benjamin Constant and the birth of French Liberalism. New York: Palgrave Macmillan, 2011.

WOOD, Dennis. Benjamin Constant: Life and Work. In: ROSENBLATT, Helena. The Cambridge Companion to Constant. Cambridge: Cambridge University Press, 2009, p. 3-19. 



\section{Resenhas}


